\title{
Discovery of Large Quantity of Acanthocytes in Ovarian Follicular Fluids of the Infertility Patients
}

\author{
Ping Xia* \\ Johns Hopkins University School of Medicine, USA \\ *Corresponding author: Ping Xia, Johns Hopkins University School of Medicine, USA
}

\begin{tabular}{|c|c|}
\hline ARTICLE INFO & ABSTRACT \\
\hline Received: 蔧 April 16, 2019 & \multirow{8}{*}{$\begin{array}{l}\text { One in six couples suffers from infertility. Its etiology in majority female patients is } \\
\text { still not clear. In this study, cells in the ovarian follicular aspirates were observed under } \\
\text { inverted microscope in more than } 200 \text { patients who underwent in vitro fertilization } \\
\text { procedures. To our great surprise, acanthocytes were found to be present in different } \\
\text { quantities in the follicular fluids of the infertility patients, especially in the patients } \\
\text { diagnosed as endometriosis. The morphology of acanthocytes were further confirmed } \\
\text { by the scanning electron microscope. The oocyte from the fragmented acanthocytes } \\
\text { presented a degenerated morphology. These findings will shed light in understanding } \\
\text { the etiology of endometriosis and unexplained infertility. To our knowledge, this is the } \\
\text { first report in the field of assisted reproductive technologies. The results have indicated } \\
\text { ovarian vascular microenvironment plays an important role in maintaining healthy } \\
\text { follicular development. Future therapies focusing on improving blood supplies to the } \\
\text { follicles would potentially improve oocyte quality for the purpose of ensuring healthy } \\
\text { babies born using in vitro fertilization approaches. }\end{array}$} \\
\hline Published: April 24, 2019 & \\
\hline itation: Ping Xia. Discovery of Large & \\
\hline uantity of Acanthocytes in Ovarian & \\
\hline ollicular Fluids of the Infertility & \\
\hline atients. Biomed J Sci \& Tech Res 17(3)- & \\
\hline 2019. BJSTR. MS.ID.003000. & \\
\hline $\begin{array}{l}\text { Keywords: Acanthocytes; Ovarian } \\
\text { Follicular Fluids; IVF; Endometriosis; } \\
\text { Scanning Electron Microscopy }\end{array}$ & \\
\hline
\end{tabular}

\section{Introduction}

The prevalence of human infertility has been increasing. With the application of in Vitro Fertilization (IVF) technologies, approximately $37 \%$ of patients can achieve pregnancies on their first attempt [1]. However, the mechanisms of infertility, especially in the category of endometriosis and the unexplained, still need extensive studies. IVF patients receive large amount of follicular stimulating hormones for the purpose of producing more than one egg. After hormonal treatments, the patients undergo a procedure of follicular fluid aspiration which allows embryologists to collect the eggs from these fluids. Our initial hypothesis was that the presence of immune cells in the follicular fluids may be related to the infertility. Therefore, we observed the cells present in the follicular fluids of over 200 patients. A surprise common feature appeared in these fluids are the star-shape cells. Our focus was redirected to these cells. They varied in sizes and some of them are smaller than the red cells. There has never been a report of these cells being present in the ovarian follicular fluids. Due to the presence of red blood cells in follicular aspirates, it is technically difficult to isolate these star-shape cells out of follicular fluids. After many failed attempts, we successfully obtained these cells by using two centrifugation speeds. Apparently, these cells were largely ignored in the past. In this study, by using the scanning electron microscope we further confirmed that these cells are acanthocytes.

\section{Materials and Methods}

The research proposal was approved by the Johns Hopkins Medicine Institutional Review Board (IRB study review number: IRB00185243) as an exempted category due to the pathological wastes were used for the study. For this type of study formal consent is not required. The follicular aspirates from the patients that underwent in vitro fertilization procedures were collected in the petri dishes immediately after the eggs were collected for the patients. The samples are deidentified except for the diagnoses. The cells were then observed under inverted microscope. Pictures of the cells in the follicular fluids from more than 200 IVF patients were taken for the future analyses.

\section{Sample preparation for Scanning Electron Microscopy observation}

The follicular fluids were centrifuged at $500 \mathrm{G}$ for $10 \mathrm{~min}$ at room temperature. The supernatant was collected and centrifuged at a higher speed (1750G) for $10 \mathrm{~min}$ at room temperature. The pellets were washed with D-PBS and then fixed in $2 \%$ paraformaldehyde, $2 \%$ glutaraldehyde, $100 \mathrm{mM}$ sodium cacodylate, $3 \mathrm{mM} \mathrm{MgCl}_{2}$ and placed on coverslips in a 6 well plate. Following overnight fixation at $4 \mathrm{oC}$, samples were rinsed in $50 \mathrm{mM}$ cacodylate buffer containing $3 \mathrm{mM} \mathrm{MgCl}_{2}$ and $2.5 \%$ sucrose, and then post-fixed with $1 \%$ osmium 
tetroxide in cacodylate buffer for 1 hour on ice in the dark. Samples were then rinsed in $\mathrm{dH}_{2} \mathrm{O}$ and dehydrated through a graded series of ethanol, and transferred to ethanol: HMDS (Hexamethyldisiloxazne Polysciences), 1:1 solution, followed by pure HMDS. Samples were then dried in a desiccator overnight. The coverslips were attached to aluminum stubs via carbon sticky tabs (Pella) and coated with 40 nm of AuPd using a Denton Vacuum Desk III sputter coater. Stubs were viewed on a LE01530 FE Scanning Electron Microscope.

\section{Results}

The appearance of the star-shaped cells in the follicular fluids is shown in Figure 1. These cells were isolated and prepared for

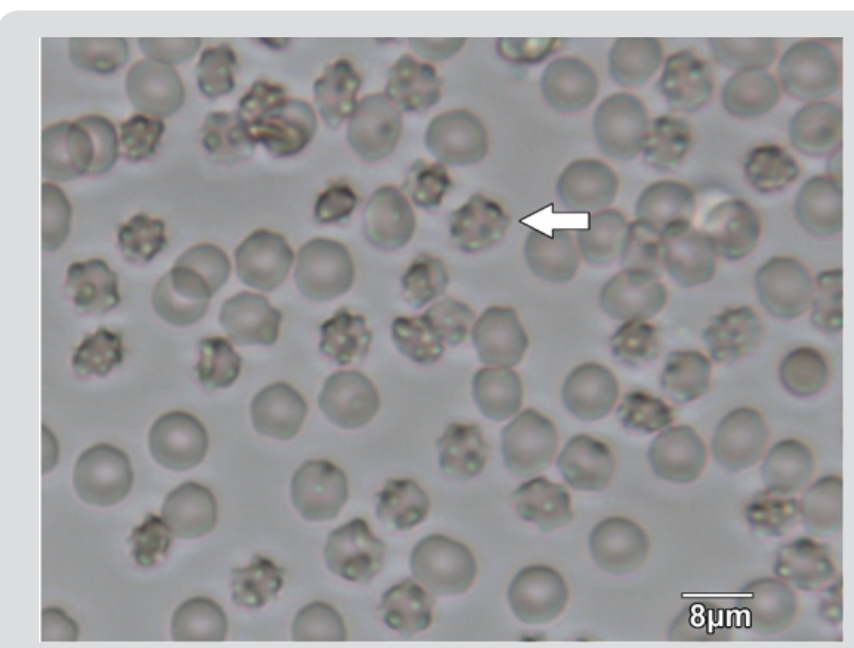

Figure 1: Star-shape cells (arrow) in follicular fluids of patients underwent treatment of controlled ovarian stimulation for the In vitro fertilization procedure. the scanning electron microscopy observation. In the Figure 2, it showed fine structures of these star-shaped cells which possess same morphology as described by Lessin et al. [2]. They were called acanthocytes. The patients with endometriosis showed consistent high proportion of acanthocytes from $95 \%$ to $100 \%$ in the follicles containing chocolate color fluid (moderate endometriosis, Figure $3 a)$, with great amount of fragmented acanthocytes seen in darker chocolate fluid (severe endometriosis, Figure $3 \mathrm{~b}$ ). The oocyte (Figure 3a) from the fluid with the moderate endometriosis showed grainy cytoplasm whereas the oocyte from the fluid with severe endometriosis presented a significant degenerated morphology (Figure 3b).

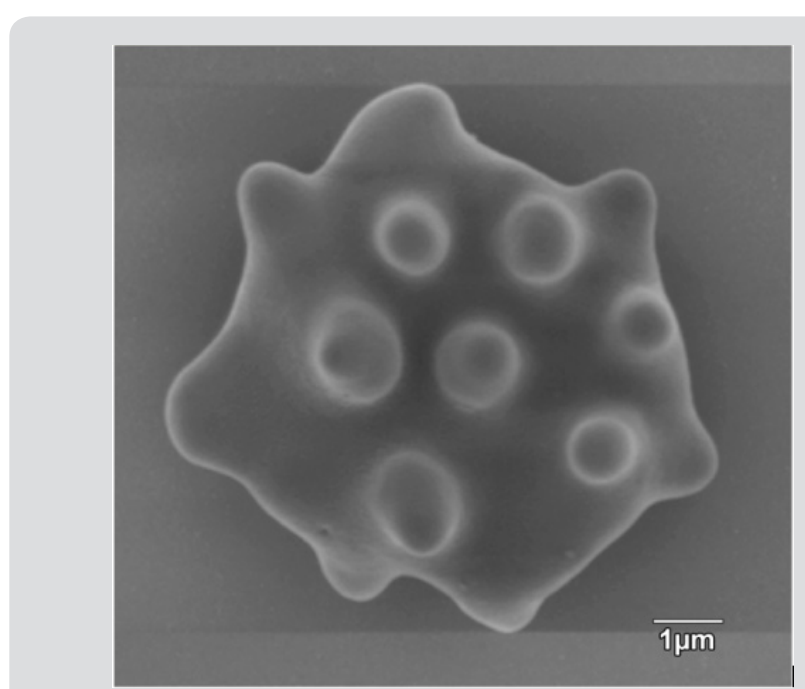

Figure 2: Scanning Electronic Microscopy image of acanthocyte as shown in Figure 1.
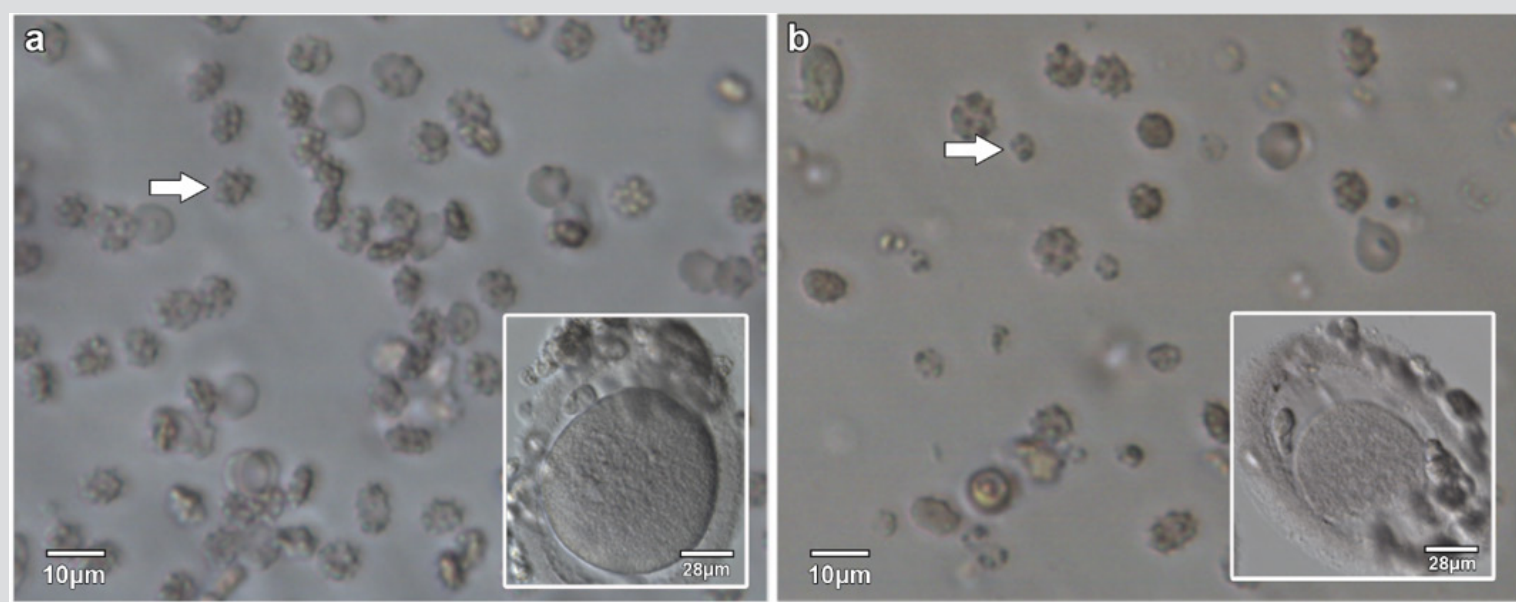

Figure 3: Acanthocytes and oocytes from follicular fluids with moderate endometriosis and severe endometriosis.

a) Acanthocytes (arrow) from follicular fluid with moderate endometriosis, with the oocyte (insert) from the same follicular fluid.

b) Acanthocytes and fragmented acanthocytes (arrow) from the follicular fluid with severe endometriosis, with the oocyte (insert) from the same follicular fluid.

\section{Discussion}

Acanthocytes, also called "Spur cell”, have thorn-like projections, irregularly distributed over the surface of red cells. Acanthocytes are found in the blood of patients in variable proportions of between 5 and $50 \%$ of red cell populations (Warner, 2009). These acanthocytes are associate with many diseases such as abetalipoproteinemia, alcoholic liver disease, postsplenectomy state and malabsorptive states [2]. We, for the first time, demonstrated that acanthocytes are associated with infertile patients who are undergoing in vitro fertilization procedures, especially in the patients diagnosed with endometriosis. 
Endometriosis is defined as chronic disorder with presence of endometrial-type mucosa outside the uterine cavity [3]. The estimated prevalence of endometriosis ranges from $2 \%$ to $15 \%$ of all reproductive aged women [4]. The precise etiopathogenesis of endometriosis is still unknown. Extensive studies suggest that genetic, hormonal, immunological and inflammatory processes are involved in the development of this condition [5]. The immune cells, such as mast cells [6] and macrophage [7], are indeed increased at endometriotic site. The serum hematological parameters were analyzed in patients with endometriosis [8] but acanthocytes were not mentioned in that study. In addition, endometriosis is associated with an increase in systemic oxidative stress, affecting the antioxidative defenses of circulating erythrocytes [7].

The mechanisms of the presence of acanthocytes in the aspirated follicular fluids will need further studies. With the blood vessels distributed around ovarian follicles, it is easily understood that the blood cells would be present in the follicular fluids when being punctured during the aspiration procedure. However, the varied amount of acanthocytes among the infertile patients (ranging from $5 \%$ to $100 \%$ ) could be associated with underlying causes of infertility which have not been realized or diagnosed. Levin et al. [9] reported erythrocyte aggregation in peripheral venous blood was largely present in the patients with ovarian hyperstimulation syndrome indicating a capillary leakage. The question that needs to be asked is, did these patients become infertile due to the primary abnormal vascular structures? Or did the vascular structures become damaged by the exogenous hormonal treatments? Clearly, the vascular damage could be the true etiology that causes abnormal microenvironment resulting in dysfunctional follicular development. The competence of oocytes inside these follicles is jeopardized. Our results support this notion that oocyte from follicular fluids with moderate endometriosis showed better morphology whereas the oocyte from severe endometriosis became degenerated. The acanthocytes in the follicular fluids with severe endometriosis were fragmented. These results indicated that the treatments for some infertile patients should focus on improving the vascular circulation and ovarian microenvironment for the purpose of improving the oocyte quality. In a recent study, Gallagher et al. [10] suggested that forms of acanthocytosis are associated with either acquired or inherited abnormalities of membrane lipids of red cells.

Deformability of red cells could cause formation of acanthocytes. Clinically, erythrocyte deformability index (DI) is used as an indicator of red blood cells. The DI of erythrocytes changes according to the follicular and ovulatory periods at mid- and late luteal phases [11], and DI is also related to the role of Gonadotropin-Releasing Hormone (GnRH) in inhibiting the synthesis of nitric oxide (NO) [12]. NO acts as a determinant of erythrocyte mechanical behavior and deformability whereas GnRH interacts with the GnRH receptor to releasing the pituitary hormones - follicular stimulating hormone and Luteinizing Hormone (LH).

Currently, it has been widely accepted to use GnRH antagonist protocol at the middle of the controlled ovarian stimulation to inhibit a premature rise in LH [13] for the purpose of preventing eggs being ovulated prior to the egg collection. Indeed, the studies have shown the GnRH antagonist protocol is associated with increased oxidative stress which was confirmed by the levels of malondialdehyde, NO, protein carbonyl, hydroxyl proline, sodium oxide dismutase, reduced glutathione, glutathione peroxidase, adenosine deaminase and xanthine oxidase [14]. NO is one of several intraovarian mediators that have been shown to influence ovarian functions, including follicular development, atresia, ovulation, steroidogenesis, oocyte quality, apoptosis, and luteal function [15]. In addition, NO may positively regulate the expression of angiogenic factors, including Vascular Endothelial Growth Factor (VEGF) and the angiogenesis in the ovaries and other tissues [16]

Reduced follicular vascularity is one of the earliest signs of atresia marked by a smaller vascular network and increased apoptosis in thecal capillaries [17]. Further studies should be conducted as regarding whether the administration of the GnRH antagonist affects the ovarian vascular structures and erythrocytes via nitric oxide pathways or other mechanisms. In addition, the alternative medicine may also benefit ovarian vascular circulation. Recent study showed that oral supplement of Ginger (Zingiber officinale) powder had significant effects on rats in increasing number of antral follicles and expression of VEGF [18]. VEGF expression in human ovaries suggests a role for this growth factor in both cyclic angiogenesis and regulation of vascular permeability, both of which are critical for ovarian folliculogenesis and normal reproductive function [19].

Several other hypotheses of acanthocytes being existed in the follicular fluids would include 1). Primary abnormal microvasculature distribution around follicles; 2). Genetic etiology; 3). Hormonal stimulation used for IVF; 4). Medicines used; 5). Abnormal lipid metabolism that could affect red cell functions; 6) Abnormal angiogenesis. Definitely, existence of acanthocytes can be used as an indicator for the infertility diagnoses, which would help decide clinical treatment plans. Improving circulation of blood supplies to the ovarian follicles would no doubt improve the oocyte quality that eventually increases the pregnancy success rates for the infertility patients. In conclusion, this is the first report that documented the presence of acanthocytes in the follicular fluids of infertile patients, especially the patients diagnosed with endometriosis. The morphology of acanthocytes were further confirmed by the scanning electron microscopy. Discovery of these cells has clinical significance in studying the mechanisms of endometriosis and etiology of unexplained infertility. In addition, the degree of acanthocytes is closely related to the oocyte morphology with significant degenerated oocyte structure in the follicular fluids containing fragmented acanthocytes. These findings provide practical values in decision-making process for taking into consideration of healthy vascular ovarian microenvironment besides the hormonal treatments for the IVF patients. Healthy follicular development is the foundation for obtaining healthy eggs with competence to develop to term $[20,21]$.

\section{Acknowledgement and Funding Information}

The author would like to thank Professor Thomas S. Kickler, MD, and Professor Le-Ming Shih, MD, PhD, for their valuable 
consultations. Both of them are faculty in the Departments of Medicine, Oncology and Pathology at the Johns Hopkins University School of Medicine. The Johns Hopkins School of Medicine Microscope core facility processed the sample for scanning electron microscopy observation. We are grateful for their efficiency in locating the cells for this study. This study has no funding support.

\section{References}

1. Wade JJ, MacLachlan V, Kovacs G (2015) The success rate of IVF has significantly improved over the last decade. Aust N Z J Obstet Gynaecol 55(5): 473-476.

2. Lessin L, Klug P, Jensen W (1976) Clinical implications of red cell shape. Adv Intern Med 21:451-500.

3. Vercellini P, Viganò P, Somigliana E, Fedele L (2014) Endometriosis: pathogenesis and treatment. Nat Rev Endocrinol 10(5): 261-275.

4. Tommassetti C and D'Hooghe T (2018) Endometriosis and infertility: insights into the causal link and management strategies. Best Pract Res Clin Obstet Gynaecol 51: 25-33.

5. Barcz E, Milewski Ł, Dziunycz P, Kamiński P, Płoski R, et al. (2012) Peritoneal cytokines and adhesion formation in endometriosis: an inverse association with vascular endothelial growth factor concentration. Fertil Steril 97(6): 1380-1386

6. Sugamata M, Ihara T, Uchiide I (2005) Increase of activated mast cells in human endometriosis. Am J Reprod Immunol 53(3): 120-125.

7. Santanam N, Murphy AA, Parthasarathy S (2002) Macrophages, oxidation and endometriosis. Ann N Y Acad Sci 955: 183-198.

8. Seckin B, Ates MC, Kirbas A, Yesilyurt H (2018) Usefulness of hematological parameters for differential diagnosis of endometriomas in adolescents/young adults and older women. Int J Adolesc Med Health.

9. Levin I, Gamzu R, Hasson Y, Lessing JB, Amit A, et al. (2004) Increased erythrocyte aggregation in ovarian hyperstimulation syndrome: a possible contributing factor in the pathophysiology of this disease. Hum Reprod 19(5): 1076-1080.

10. Gallagher PG (2018) Red blood cell membrane disorders. In: Hoffman R, Benz EJ, Silberstein LE et al. Hematology: Basic Principles and Practice ( $7^{\text {th }}$ Edn), Elsevier, Philadelphia, USA, pp. 626-647.

\section{ISSN: 2574-1241}

DOI: 10.26717/BJSTR.2019.17.003000

Ping Xia. Biomed J Sci \& Tech Res

(C) This work is licensed under Creative

Submission Link: https://biomedres.us/submit-manuscript.php
11. Solerte SB, Fioravanti M, Spinillo A, Ferrari E, Guaschino S (1988) Association between hormonal and haemorheological changes during the menstrual cycle in healthy women. Br J Obstet Gynaecol 95(12): 1305-1308.

12. Ekerhovd E, Enskog A, Caidahl K, Klintland N, Nilsson L, et al. (2001) Plasma concentrations of nitrate during the menstrual cycle, ovarian stimulation and ovarian hyperstimulation syndrome. Hum Reprod 16(7): 1334-1339.

13. Tarlatzis BC, Fauser BC, Kolibianakis EM, Diedrich K, Devroey P (2006) $\mathrm{GnRH}$ antagonists in ovarian stimulation for IVF. Hum Reprod Update 12(4): 333-340.

14. Celik E, Celik O, Kumbak B, Yilmaz E, Turkcuoglu I, et al. (2012) A comparative study on oxidative and antioxidative markers of serum and follicular fluid in GnRH angonist and antagonist cycles. J Assist Reprod Genet 29(11): 1175-1183.

15. Grazul Bilska AT, Navanukraw C, Johnson ML, Arnold DA, Reynolds LP, et al. (2006) Expression of endothelial nitric oxide synthase in the ovine ovary throughout the estrous cycle. Reproduction 132(4): 579-587.

16. Reynolds LP, Grazul Bilska AT, Redmer DA (2000) Angiogenesis in the corpus luteum. Endocrine 12(1): 1-9.

17. Mattioli M, Barboni B, Turriani M, Baleati G, Zannoni A, et al. (2001) Follicle activation involves vascular endothelial growth factor production and increased blood vessel extension. Biol Reprod 65(4): 1014-1019.

18. Yilmaz N, Seven B, Timur H, Yorganci A, Inal HA, et al. (2018) Ginger (zingiber officinale) might improve female fertility: a rat model. J Chin Med Assoc 81(10): 905-911.

19. Geva E, Jaffe RB (2000) Role of vascular endothelial growth factor in ovarian physiology and pathology. Fertil Steril 74(3): 429-438.

20. Bordin L, Fiore C, Donà G, Andrisani A, Ambrosini G, et al. (2010) Evaluation of erythrocyte band 3 phosphotyrosine level, glutathione content, CA-125 and human epididymal secretory protein E4 as combined parameters in endometriosis. Fertil Steril 94(5): 1616-1621.

21. Warner TT, Hammans SR (2009) Practical Guide to Neurogenetics. Saunders Elsevier, Philadelphia, USA.

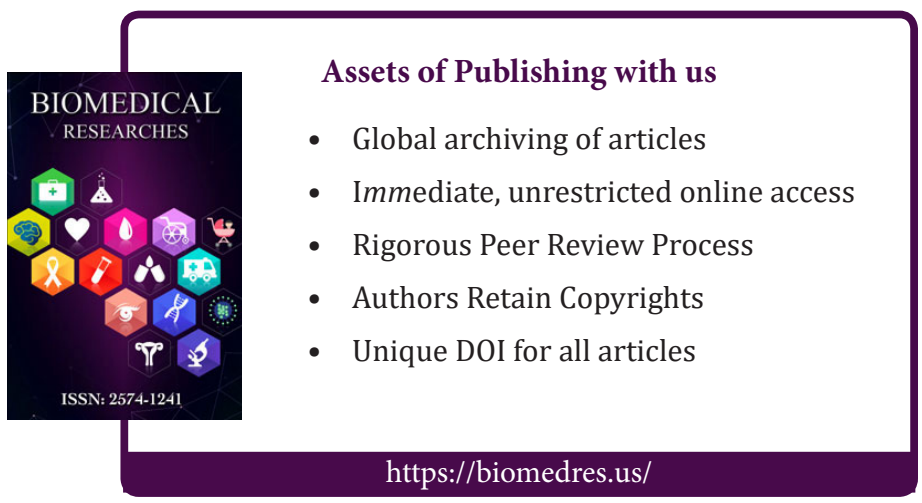

